EXEMPLARIa Classica

Journal of Classical Philology

19, 2015, pp. 149-153

ISSN 1699-3225

\title{
EL ASNO REDIMIDO: NOTAS AL NUEVO COMENTARIO AL LIBRO XI DE LAS METAMORFOSIS DE APULEYO
}

\author{
W. H. Keulen - S. Tilg - L. Nicolini - L. Graverini - S. J.Harrison
} - S. Panayotakis - D. van Mal-Maeder, Apuleius Madaurensis. Metamorphoses. Book XI. The Isis Book. Text, Introduction and Commentary. Essays by F. Drews, W.S. Smith and U. EgelhaafGaiser. Groningen Commentaries on Apuleius, Leiden - Boston: Brill, 2015, VIII + 681 pp. ISBN 978-90-0426-920-0.

El presente volumen culmina una extensa serie de publicaciones, los Groningen Commentaries on Apuleius, con un nuevo comentario del último libro de Metamorfosis a cargo de un selecto equipo internacional de filólogos expertos en este autor y que ya han producido algunas de las aportaciones más relevantes en este campo en los últimos años.

No se trata simplemente de culminar una colección, los últimos comentarios sobre el tema, de $1975^{1}$, estaban necesitados de una actualización evidente $\mathrm{y}$, sobre todo, de completar la información contenida en ellos añadiéndoles cuestiones lingüísticas y, más que nada, literarias que, por una u otra razón no estaban presentes en ellos. La exorbitante cantidad de estudios sobre novela antigua y concretamente sobre Apuleyo que ha aparecido en los últimos años y la complejidad desde cualquier punto de vista del libro XI hacían aconsejable obviamente que fueran varios los autores de una obra que pretende ser exhaustiva además de innovadora. Los resultados del trabajo, gestado durante años y que ya había producido publicaciones previas ${ }^{2}$, no decepcionan en absoluto.

${ }^{1}$ El de J. Gwyn Griffiths (Apuleius of Madauros. The Isis Book (Metamorphoses, Book XI), Leiden 1975), una obra magnífica que, entre otros logros, había realizado un profundo análisis del texto desde el punto de vista de la historia de las religiones comparándolo con otras fuentes, especialmente egipcias, y el de Jean-Claude Fredouille (Apulei Metamorphoseon liber XI, Paris 1975), que más que un comentario propiamente dicho, es una edición anotada encuadrada dentro de la colección Érasme, aunque tan extensa y ricamente explicada que se aproxima mucho a esta categoría.

${ }^{2}$ Especialmente W. Keulen - U. Egelhaaf-Gaiser, Aspects of Apuleius' Golden Ass. Volume III: the Isis Book, Leiden · Boston 2012, en adelante, AAGA 3. Son constantes a lo largo del comentario las referencias a esta colección de estudios. 
Tras unos acknowledgements a cargo de los editores, Keulen y EgelhaafGeiser, que, expresando el reconocimiento a distintas personas e instituciones, narra en cierta forma la historia de cómo se escribió el libro a través de los coloquios, seminarios y reuniones científicas en los que se gestó, se abre una larga, densa y valiosa introducción (1-67).

Las primeras páginas presentan una síntesis crítica de los diversos enfoques con los que se aborda el libro XI: la que lo considera ante todo como fuente para la historia de las religiones, las interpretaciones alegóricas, religiosas y platónicas, los análisis literarios, entre los que se cuentan los basados en la narratología, y las aproximaciones histórico-culturales. Sigue un amplio resumen y esquema del libro (9-11) con unas observaciones sobre las falsas conclusiones y unas páginas sobre técnica narrativa. Interesante la sección sobre tiempo y espacio, temas que han suscitado no pocas publicaciones recientes (21-33), y la caracterización de los personajes ${ }^{3}$. En la parte dedicada a las relaciones con otros textos cuentan con apartados específicos los relativos a Lucrecio, el Onos griego, las otras novelas antiguas y la épica.

En general la introducción proporciona un resumen utilísimo de las aportaciones de la crítica, casi siempre la más reciente, sobre cada uno de los aspectos tratados, con abundantes y muy completas notas que dan cuenta prácticamente de toda la bibliografía disponible. Quizá lo único que se podría achacar, a pesar de que, como se ha visto, es una excelente herramienta para el conocimiento del libro XI, es que pretende, por una parte, hacer un recorrido por temas esenciales en el relato de manera aséptica, presentando los datos a partir siempre del texto e ilustrándolos con las interpretaciones de los estudiosos, $y$, por otra, contiene de manera constante observaciones particulares que justifican las explicaciones y enfoques del comentario ${ }^{4}$. En la presentación de un libro como este, con unos ensayos finales específicos, y puesto que se ha editado previamente un volumen de estudios ( $A A G A 3)$, probablemente hubiera sido preferible atenerse a un tono más objetivo que diera al lector instrumentos de comprensión de la obra junto con una buena síntesis de las ideas vertidas por los numerosos filólogos que se han ocupado de ella. No habría en ese caso tantas afirmaciones enormemente hipotéticas 5 .

${ }^{3}$ En más de un pasaje se cita como forthcoming el libro colectivo recientemente aparecido de S. J. Harrison (ed.), Characterization in Apuleius' Metamophoses. Nine Studies, Cambridge 2015.

${ }^{4} \mathrm{Me}$ parecen singularmente estimulantes, por ejemplo, la relación entre la evolución de Lucio y la del libro XI con respecto al resto de la novela (p. 39). Hay otros muchos casos que, sencillamente, son discutibles, véase e. g. la nota 159

${ }^{5}$ Alguna consideración sobre el final de la novela en la p. 47, por más que el tema haya suscitado no pocas conjeturas. No creo que falten ni siquiera algunas frases, como piensa Zimmerman $(A A G A 3,27)$ : en cualquier caso, son suposiciones perfectamente superfluas. Véanse también las conclusiones de p. 49 sobre la presencia de una referencia autobiográfica en el modelo perdido y las observaciones completas sobre el tema en 499. 
La excepción a estos últimos reparos es el capítulo dedicado a la lengua y estilo $^{6}$, irreprochable desde cualquier punto de vista. Curiosa, para acabar, la sección 7.3 sobre las cualidades cinematográficas del libro. En cualquier caso, estas excelentes páginas de la introducción suponen tanto una forma inmejorable de adentrarse en el libro como una certera puesta al día sobre gran parte de sus motivos más sobresalientes, que forman, además, una parte imprescindible del universo apuleyano.

A continuación de la introducción, una nota crítica advierte que se ha cambiado el texto latino de referencia en los GCA, la tercera edición de Helm en la Teubner, de 1955, por el de Zimmerman en Oxford Classical Texts del $2012^{7}$. Tras alguna cuestión como la ortografía, se lista una serie de divergencias entre este y el que se reproduce y comenta en el libro y que aparecen discutidas en su lugar correspondiente. Entre estas hay algunas que suponen una clara mejora. Así, por ejemplo, creo que es bueno volver a la adición imprescindible de Bursian en 3.5 - porrectis. <uestis $>-$ y no aceptar la de Zimmerman - porrectis <ornata. uestis>-, que la complica innecesaria y temerariamente con la lectura de Castiglioni -<ornata. sed et uestis>-, tal como se ve en el comentario (p. 134), exhaustivo salvo por la omisión de Arena $1999^{8}$. La excelente conjetura de Haupt en 9.4 - facticiies con casi total seguridad lo que escribió Apuleyo y era necesario restituirla aquí, como habían admitido Helm y Griffths, por ejemplo: Zimmerman se dejó arrastrar por manuscritos posteriores que no presentan más que una simple banalización. Igualmente laudables son la vuelta a $\mathbf{F}$ en 6.3 (mearum) en vez de la superflua corrección de Scriverius (earum). Tampoco tenía sentido la conjetura de Nicolini 2010 en 28.4 (RFIC 138, 194-7), felizmente desechada. Es atractiva sin duda la corrección uehentem de Frassinetti (Corpus Paravianum 1960, 323) por uehebatur en 8.4, aunque, por cierto, este se limitó a sugerirla en el aparato crítico: lo que no se entiende es que no se cite, además de los pasajes de Gelio (2.2.13; 5.6.27) y el de Cicerón Brutus 331 , que se transcribe equivocadamente en vez del primero, el único paralelo que hay en Apuleyo, Metamorfosis 1.2.2, cf. Keulen 2007, 100. Sensato el mantenimiento de la solución de Helm en 27.6 y el comentario pertinente.

Algún pasaje genera más dudas, así el iam dudum detestabilis de Robertson en 6.2, en vez de detestabilis iam dudum (Zimmerman, Helm): es difícil buscar paralelos, al menos en prosa, para la construcción, pero tampoco están claros en $\mathrm{F}$ los signos con los que, según Robertson, se indicó el cambio de lugar y que los demás manuscritos no corroboran9. El comentario sobre fulgebat en 16.8 es razonablemente cauto, como la vuelta

\footnotetext{
${ }^{6}$ El 7, sobre todo las páginas 58-66, sólidamente ancladas en el análisis del texto.

${ }^{7}$ Sobre esta edición véase la reseña en ExClass 2013, 401-11.

${ }^{8}$ A la que, por cierto, tampoco se cita en 9.4 .

9 Aunque $\varphi$ presenta un desconcertante iam detestabilis dudum, A y U, por ejemplo, trasmiten lo mismo que $\mathrm{F}$.
} 
a la lectura de $\mathbf{F}$ ante la incertidumbre de los datos. También es comprensible el mantenimiento de $u t$ en 20.3 de acuerdo con la contundente defensa de Fredouille 1975, 98. La lectura serebat de Oudendorp (1786, 817) en 30.4 es aceptable y mucho mejor que otras, aunque quizá la de Beroaldo (1500, 280r), disserebat, merecería mayor atención. Poco antes, en este mismo capítulo se ha adoptado una conjetura de Harrison, quin, por quam de $\mathbf{F}$ (o quae de Helm): las objeciones del comentario a las lecturas tradicionales están bien razonadas y la propuesta es sugestiva, sin embargo, deberían haber aportado ejemplos más cercanos de uso en estilo indirecto, porque, definitivamente, el valor de quin en Livio 3.61 .4 es muy distinto (OLD s. v. A 1) y, por otro lado, no se ve muy claro nunc en la traducción. Mientras tanto, la lectura de Helm posiblemente sigue siendo la más indicada ${ }^{10}$. Mucho más insegura, aunque ciertamente digna de atención, es la propuesta, también de Harrison, de escribir Cecropiam en vez de Cecropeiam, en contra de la tradición manuscrita y todos los editores anteriores.

Por otro lado, hay algunas correcciones completamente gratuitas. Así, los argumentos a favor de laureis - por aureis- en 235 o no son nuevos o son poco convincentes, por lo debería haber prevalecido la defensa de Augello ${ }^{11}$ y Zimmerman en AAGA 3 (16-7). Tampoco resulta muy adecuado cuiusce modi (16.9) por huiusce modi, que no es ajeno tampoco al uso apuleyano (cf. 1.5.3, 9.18.4, apol. 13.2) y proporciona buen sentido: las razones para corregirlo, de acuerdo con Brantius, que solo parece conocer 11.7.32, son insuficientes. La mismas observaciones sobre $29.4^{13}$ deberían haber hecho descartar el laetus de $\mathrm{Helm}^{14}$ por el gusto del autor por las expresiones redundantes, como señala Fredouille $(1975,134)$ : Berhhard ${ }^{15}$ lista incluso esta expresión entre los numerosos casos de adjetivos empleados de forma pleonástica con sustantivos. Por otro lado, debería revisarse el razonamiento para corregir perlato en 7.1 (190) y explicar por qué es distinto de perferens en 1.14.3 o por qué no se puede aplicar lo dicho ya por Keulen en GCA 2007, 286-7, donde, por cierto, se traduce por relating. No es fácil, por otro lado, decidirse entre labentes en 25.4 (Hildebrand 1842, I 1080) o el latentes de los manuscritos, pero el argumento de que los otros verbos de la frase (meantes... errantes... natantes) expresan movimiento es muy endeble y es un disparate alegar la sintaxis de solo sin preposición: ni se puede esperar otra cosa entre

${ }^{10}$ Las críticas son fácilmente soslayables: véase, por ejemplo, la traducción de quae nunc de Walsh $(1994,240)$, as now, exactamente igual, por cierto, que Griffiths 1975, 109.

${ }^{11}$ G. Augello, Studi Apuleiani. Problemi di testo e loci vexati delle Metamorfosi, Palermo 1977, 228-9.

${ }^{12}$ En J. Rutgersius - E. Puteanus - J. Brantius, Spicilegia in Apuleium, p. 76 de su parte, incluido en la edición de Elmenhorst (Francofurti 1621).

${ }^{13}$ Y que se repite a propósito de 30.4 en p. 511.

${ }^{14}$ Efectivamente, hay que atribuir a Helm la conjetura: en todo caso, es incontestable que no es una lectio vulgata, porque no se encuentra en ediciones o manuscritos.

${ }^{15}$ M. Bernhard, Der Stil des Apuleius von Madaura, Stuttgart 1927, 176. 
caelo... montibus... ponto ni es una construcción insólita, aunque sí más propia de la poesía, cf. e. g. Verg. A. 10.805-6; Hor. epod. 9.19; Ov. ars 1.569; Phaed. 4.6.13. Nada, en todo caso, impropio del elevado estilo hímnico del capítulo que con tanto acierto se analiza en pp. 425-6, 430 o 433.

En general los comentarios sobre otros problemas en el texto están excelentemente argumentados, aportan toda la información pertinente y toman partido abiertamente por las soluciones más razonables ${ }^{16}$. Da la impresión, por ejemplo, de que en 13.2 (cupidus promissi), hasta donde se puede dar por segura una cuestión como esta, dejan el asunto zanjado. Con respecto a prudentia / prouidentia en 15.4 (287-8) se reflejan honradamente las dudas e inseguridades que genera esta disyuntiva, al igual que en 16.8; sin embargo, por lo que toca a 16.5 (ibi deum simulacris) se echa de menos un razonamiento serio y completo, lo mismo que, poco más adelante, en ritu (16.10), que parece una lectura tan banal como falta de fundamento.

El problema de 23.5 (contraherent... curiositatis), en el que se acaba aceptando la intervención de Nicolini (lingua[e]<illicitae intemperantiae ista $>^{17}$ ), se desarrolla en un largo comentario (pp. 394-6), en principio completo y adecuado ${ }^{18}$, que termina de forma desconcertante admitiendo que la lectura de Helm, prácticamente lo mismo que los manuscritos, es understandable but very awkward, mientras que queda más claro añadiendo varios términos. Existen las mismas posibilidades de que se haya dado así con lo que escribió Apuleyo que con la propuesta de Van der Vliet - lingua[e] <ista impiae loquacitatis>- o con cualquier otra: si el pasaje es inviable tal como se ha trasmitido, que no es el caso, existe la posibilidad de señalar una laguna, pero si no es así, no debería alterarse. También se deja sentir la influencia de Zimmerman 2012 en 30.1 a favor de una lectura normalizadora (largitionibus) cuando la de los manuscritos (largitus), por muy rara que sea, cuenta con otro testimonio.

Por lo que respecta al comentario en general, es característico del volumen las largas introducciones a determinados temas que se suscitan a lo largo del libro: el primero, por ejemplo, es una presentación de varias páginas (83-6) de la diosa Luna y su importancia en la magia. Como otras muchas a lo largo del libro, es una exposición solvente, completa e ilustrada con la bibliografía adecuada.

${ }^{16}$ Por poner algún ejemplo más, aunque es norma general, véanse las observaciones a 22.1 (quot) o los extensos tratamientos de suscitare (29.1) y mensura <re>rum collatis (30.1). Por supuesto, también hay excepciones: no se puede despachar un razonamiento escribiendo simplemente que una construcción parece imposible (444). Los errores en datos sobre manuscritos son rarísimos e insignificantes: por alegar uno, en p. 116 la lectura de una segunda mano al margen (nudis), que se localiza en $\mathrm{F}$, está en $\varphi$.

${ }^{17}$ En Philologus 154, 2010, 152-4, también admitida por Zimmerman 2012.

${ }^{18}$ Quizá el punto más débil es el problema con el plural linguae, que Hildebrand (1842, I 1073) dejó resuelto: Linguae vel in universum ad omnes referri potest, qui talia provulgarent, vel ad solum Lucium, plurali pro singulari ob antecedens aures posito. 
A esta siguen tres en capítulo 2 sobre la plegaria de Lucio, su retórica y la presencia de la Luna junto a otras diosas, la descripción de la diosa (3) comparada con Venus y Fótide, con especial atención al cabello, la presentación de Isis (5), a la que se reacciona en el 7, los anteludia del 8 con un buen resumen de las interpretaciones que se han dado, la transformación del asno, con especial atención al influjo ovidiano (13), la alocución del sacerdote junto con su importancia para la interpretación de Metamorfosis (15), las visiones opuestas de Lucio en 16, la descripción de los ritos (23), la celebración pública de 24 o el himno de 25, Osiris (27), la segunda iniciación (28) y la tercera (29) hasta el problema del final de la obra (30).

Me parece un claro acierto esta disposición: los temas son suficientemente importantes y requieren un tratamiento más extenso que el que se suele dar comentando expresiones aisladas en el conjunto de un libro de este tipo y, por otra parte, es mucho más útil y cómodo para el lector localizarlos en los capítulos en los que aparecen que situarlos en la introducción o relegarlos a apéndices. Las numerosas referencias cruzadas y los espléndidos índices hacen que tan trascendental material, repartido por todo el volumen, esté siempre localizable. Incluso podrían haberse aumentado estos párrafos introductorios para tratar, por ejemplo, el nombre del sacerdote Mitra (22.3), cuyo sentido se discute concienzudamente en pp.371-3, o las explicaciones de Madaurensem (27.9), que se recopilan en 465-7.

El comentario de Griffiths de 1975 ha sido hasta este momento y con todos los honores el libro de referencia para Metamorfosis XI: es un excelente volumen producto de un gran filólogo e intelectual y contiene los resultados de una investigación de primer nivel: supuso un avance trascendental en los estudios apuleyanos y todavía hoy merece consultarse y citarse para más de un pasaje concreto, pero definitivamente el volumen de los GCA lo ha superado, como cabía suponer, de forma incuestionable prácticamente en cualquier aspecto. La mayor parte de lo que aporta este en análisis de los motivos literarios y examen de la estructura formal, por no hablar de los paralelos aducidos, o se encontraba mucho menos desarrollado en el primero o sencillamente estaba ausente. Véanse como ejemplos las anotaciones sobre 1.4 y el baño purificador y Pitágoras (100-3), el análisis, mucho más rico, de la transformación de Lucio en el capítulo 13, con mayor insistencia en Ovidio Metamorfosis y analogía con el libro 3, o la nota más completa sobre el navigium Isidis (314).

En general, el estudioso que acuda al libro a buscar información y análisis de un pasaje particular encontrará sin duda lo que busca y mucho más. Por supuesto que hay partes en las que la crítica no se pone de acuerdo o de las que sencillamente se ignora el sentido y en los que a los editores solo les queda trasmitir las dudas ${ }^{19}$. En otros casos, en cambio, se podía razonablemente

${ }^{19}$ Caso de decurionum quinquennales en 11.30.4. 
esperar un comentario más detallado, como por ejemplo al tratar los dos tipos de árboles de 7.5: ¿hay paralelos para esta división?, ¿se podrían relacionar con pecuina et ferina de 1.2 (p. 94-5) y, como estos, con algún elemento en Lucrecio? Después del impresionante análisis de la descripción de Isis en el capítulo 3 quizá se eche de menos una explicación más detallada del comienzo de esta y, concretamente, de su aparición después de que el protagonista caiga de nuevo en un profundo sueño y el significado de este hecho. A propósito de esto mismo, resaltaría la profunda ironía del canto de agradecimiento en honor de la diosa cuando la transformación se produce por el mismo procedimiento mágico que determinó la conversión en asno (pp. 265-7). Tampoco se ha relacionado los objetos de culto secretos de 11.2 con los que se mencionan en apol. 56.1. Se podría haber analizado con mayor detenimiento la función que ocupa la recuperación del caballo blanco en el capítulo 20, que no se encuentra en el Onos, y el cándido ${ }^{20}$ reconocimiento de este hecho como cumplimiento del sueño premonitorio. En 24.2 (pp. 406 y 409) se llama la atención con toda razón sobre las flagrantes semejanzas entre la exhibición de Lucio tras su iniciación y la estatua de Batilo en flor. 15.8, pero apenas se intentan explicar o justificar.

En otros casos, quizá se podría haber dado mayor consistencia a algunas observaciones con citas o argumentos adicionales. Así, a apol. 52.4 (6.4: criminabitur, p. 181), una nota certera, debería habérsele añadido 3.1 y 53.1 . Más adelante, aunque estoy totalmente de acuerdo con las consideraciones sobre fascibus de 8.3, no hubiera estado mal aducir el paralelo de Mommsen que sí proporciona Griffiths, de la misma forma que se podrían haber buscado otros ejemplos en 10.1 sobre el uso religioso de ungüentos y perfumes por parte de los devotos ${ }^{21}$, no de tipo convival, como son inequívocamente los que aparecen, ni relacionados con la adoración de las estatuas, a lo que se alude equivocadamente a propósito de $9.3(221)^{22}$. En 9.2-3 se cita acertadamente el paralelo más significativo - Aug. civ. 6.10.2-, pero no se advierte que este está reproduciendo palabras de Séneca, y en 10.4, al comentar Mercuriale... caduceum tampoco se observa que, curiosísimamente, el caduceo es el único elemento típico del dios que falta en la descripción de apol. 63.7-8. A propósito de destinatae (21.6) hubiera resultado interesante comparar la expresión con otros lugares de la novela — no solo 6.31.2, sino e. g. 1.14.2 o 4.34.1-, aunque no quepa en estos el matiz, quizá discutible, de voluntariedad.

${ }^{20} D R A E$ s. v. 1-2; OLD s. v. candidus 8.

${ }^{21}$ Cf. e. g. M. Beard - J. North - S. Price, Religions of Rome, 2 vols., Cambridge 2007 (= 1998), II 88.

${ }^{22}$ Se esparcen perfumes por las calles, obviamente, en honor de la diosa y, como tantas otras veces, como parte del espectáculo, pero no se trata aquí del cuidado directo de su estatua: sería más adecuado comparar este lugar con 6.24.3 (spargebant balsama / balsamo... conspargebant) e incluso con el uso que se hacía en diversas funciones (10.34.2), cf. GCA 2000, 403, y el empleo ambivalente en Sall. Hist. 2.70 M. 
Ante praefatus... ueniam, además de los paralelos en Metamorfosis, bien tratados, tiene un carácter religioso innegable flor.1.2.

El aparato bibliográfico y la pericia y conocimientos de los autores dejan poco lugar, por no decir casi ninguno, a mejoras o correcciones. Entre los muy escasos que ha suscitado esta lectura alegaría los siguientes:

Llama la atención que no se aduzca un testimonio que precisamente se acaba de citar (Apul. Soc. 117-8 Oud.) en la discusión sobre el significado de solis en 2.3. Lo que Bianchi 2007 dice exactamente y se cita a propósito de 3.4 (p. 131) es que no es una característica general de Isis representarla con una especie de tirabuzones y que estos podían tener origen griego ${ }^{23}$. Creo que la preferencia por magnae en 8.1 obedece además a cuestiones fonéticas y a la imitación de la marcha de la pompa, cf. Griffiths 1975, 171. A 20.5 perstrepunt se le debía haber adjuntado el strepit de flor. 18.37, también en obvio contexto religioso, descartado con demasiada ligereza en p. $271^{24}$. Ni por asomo tiene el mismo sentido detergo en 24.7 , que expresa un acto de profundo sentimiento religioso, y en apol.59.1. Al contrario de lo que se afirma en p. 159, los cretenses sí eran especialmente apreciados como arqueros en los ejércitos romanos ${ }^{25}$, por lo que el epíteto sagittiferi es plenamente convencional.

Es loable que se hayan citado a los filólogos anteriores a Oudendorp (1786) y Hildebrand (1842) con el año de sus ediciones, pero, teniendo en cuenta la facilidad que existe en estos momentos para consultar libros antiguos, hubiera cabido también la posibilidad de adjuntar el número de página, recuperando así, aunque sea esporádicamente, un material valiosísimo y rindiendo un pequeño homenaje de pietas científica a unos estudiosos excepcionales ${ }^{26}$.

Completan el volumen tres ensayos, obra de sendos investigadores - los dos primeros ajenos al grupo de autores, la tercera, editora-, que aportan una interpretación más peculiar, como es lógico, de algunos aspectos. Es discutible que este sea el lugar apropiado para este tipo de publicaciones, aunque ciertamente contribuyen a ampliar la visión sobre el libro XI. En el primero de ellos -'A Platonic reading of the Isis Book'-, F. Drews rastrea el fundamento platónico, tanto directamente a partir de la obra del pensador griego como, sobre todo, de la obra filosófica del mismo Apuleyo, de la concepción de Isis

${ }^{23}$ «I would, therefore, suggest that the possible origins of the corkscrew locks so characteristic of the five images of Isis which we have been discussing are Greek» (p. 486). Esto al menos hace dudar de la automática asociación de este tipo de cabello con África. Téngase en cuenta, incidentalmente, que Egipto para los antiguos no era parte de este continente.

${ }^{24}$ Los paralelos aducidos por Hijmans ("Apuleius orator: 'Pro se de magia' and 'Florida'", $A N R W$ II 34.2, 1994, pp. 1721) son dignos de tenerse en cuenta ante las numerosas correcciones simplificadoras, sobre todo Front. ep. 3.10.2 [p. 43.17 Van den Hout].

${ }^{25}$ Cf. G. M. Paul, A Historical Commentary on Sallust's Bellum Jugurthinum, Liverpool 1985, 141-2, y e. g. Plut. C. Gr. 16.

${ }^{26}$ Es verdad que las inapreciables anotaciones de Oudendorp, a las que generalmente se acude para estudiar la crítica de los siglos XV-XVIII, son prácticamente siempre exactas, pero alguna vez se escapa algún detalle, especialmente cuando no se trata de crítica textual. 
y Osiris como dioses y la diferencia entre ambas ${ }^{27}$, la visión de la diosa como madre del tiempo y la naturaleza y la que se deduce del discurso del sacerdote en el capítulo 15 y su trascendencia para la interpretación de la novela. Aunque contiene ideas interesantes, la selección de textos y su interpretación parece muchas veces sesgada en favor de una determinada conclusión ${ }^{28}$. Por ejemplo, sorprende que, al hablar de una divinidad única, no se aluda a apol. $64 \mathrm{ni}$ se explique si hay relación con Metamorfosis XI, también que se tome el concepto de daemon de forma parcial, cuando en realidad no es fácil percibir una definición absolutamente coherente en el mismo Apuleyo ${ }^{29}$.

El segundo artículo, The Isis Book and Contemporary Jewish/ Christian Literature, de Warren S. Smith trata de establecer paralelos entre las experiencias religiosas del libro XI y textos contemporáneos judíos y cristianos. En principio la idea es estimulante, el problema es que para que las semejanzas sean perceptibles hay que manejar conceptos tan amplios que comprometen la verosimilitud de tales parecidos ${ }^{30}$. El tercer ensayo -Ulrike Egelhaaf-Gaiser, "A World of Images: Visual Geography in the Isis Temple at Pompeii and in the Isis Book of Apuleius"- pretende, en medio de una revisión crítica de enfoques en la investigación, tomar del análisis de las artes visuales algunos conceptos claves para aplicarlos tanto a las pinturas del Iseo pompeyano como a la procesión de Isis en el libro $\mathrm{XI}^{31}$. Las únicas imágenes del volumen (pp. 563-6) están destinadas a ilustrar este artículo.

El libro, por otra parte, presenta unas características muy particulares: no solo son varios los autores, sino que el material se presenta distribuido de forma muy peculiar entre la rica introducción, las presentaciones que abren muchos capítulos, el comentario en sí y los ensayos que cierran la obra, por no hablar de las citas de $A A G A 3$. El riesgo evidente era que la información se perdiera o se repitiera innecesariamente en uno u otro punto, o bien que el lector, en un instrumento fundamentalmente de consulta, no supiera a dónde acudir; sin embargo, gracias a un trabajo de edición realizado con un cuidado y una meticulosidad impecables, que ha provisto a la obra de constantes reenvíos de una parte a otra y magníficos índices, se ha

${ }^{27}$ Ciertamente demasiado sutil (520), por no decir artificial.

${ }^{28}$ La expresión redeunt tempora, por ejemplo, admite como mínimo otras interpretaciones: véase el comentario (p. 433).

${ }^{29}$ Solo la escandalosa diferencia en la clasificación de Osiris como el mayor de los dioses (Met. 11.30.3) o simple daemon en De deo Socratis 15 (154 Oud.), como señala Beaujeu 1983, 391, ilustra bien las incoherencias del pensamiento apuleyano.

${ }^{30}$ Obsérvese por ejemplo la conclusión (p. 542): los parecidos - la idea de conversión, la sumisión a la voluntad divina, etc.- son intrascendentemente generales, mientras que las diferencias, obvias, podrían enfocarse tanto en contra de las ideas judías o cristianas como de cualquier otra forma.

${ }^{31}$ En concreto se trata de la relación entre narración y descripción, el contraste entre el mundo cotidiano y el ajeno, la dinámica del observador y la imagen y la presencia de esta en un contexto espacial. 
conseguido sortear este escollo con éxito y, aunque siempre existan algunas incongruencias ${ }^{32}$, prestarle al comentario la necesaria solidez y facilidad de manejo.

El apartado de bibliografía es impresionante: cuarenta densas páginas de referencias entre las que es difícil echar de menos alguna obra, particularmente entre la producción más reciente ${ }^{33}$. Son tres los índices, exhaustivos, que rematan el volumen: index rerum, nominum et verborum y locorum. Desde otro punto de vista, se trata de una edición, en consonancia con los anteriores volúmenes de la serie o incluso en mayor medida, muy cuidada y en la que están prácticamente ausentes las erratas ${ }^{34}$.

El comentario al libro XI de las Metamorfosis es, para concluir, un libro espléndido, un auténtico compendio de la mejor filología y un instrumento absolutamente imprescindible para los estudios sobre Apuleyo y la novela antigua y merecedor, por tanto, de un lugar de honor en la bibliografía sobre Filología clásica.

\author{
Juan Martos Fernández \\ Universidad de Sevilla \\ juanmartosf@us.es
}

\footnotetext{
${ }^{32}$ Señalaría, por ejemplo, que no hubiera venido mal remitir en 9.2 nitentibus speculis (p. 220) a 3.4 (132) ni aludir en la aliteración de 11.1 (p. 236) a otros momentos de la procesión, como 8.1; por otro lado, se podrían haber aligerado los comentarios sobre algunos puntos (e. g. prouidentia), que llegan a ser redundantes, agrupándolos en algunos lugares significativos. En cualquier caso, esto es la excepción.

${ }^{33}$ Quizá mereciera la pena citar todavía el estudio de Abate sobre diminutivos y, con toda seguridad, el de Abt sobre magia (Die Apologie von Apuleius von Madaura und die antike Zauberei, Giessen 1908), por ejemplo en p. 85 (123-30); también Ruiz de Elvira 1954, 116 a propósito de 11.18.6 o Moreno Soldevila 2011 (Diccionario de motivos amatorios en la literatura latina, Huelva) para ilustrar, entre otros aspectos, como descripción de la belleza de la amada el tema del cabello en el capítulo 3. Faltan, desde luego, Gallaher 1993 (JR 73), PucciniDelbey 2003, Marangoni en Incontri triestini di filologia classica 5, 2005-2006, o Hidalgo de la Vega en Studia historica. Historia antigua 25, 2007: quizá sea demasiado reciente La Barbera 2013 en $M D$ 71. Por otra parte se remite a Lunais 1979 o Platt 2011, pero no aparecen en la bibliografía.

${ }^{34}$ Es difícil que, entre tantos, no baile algún número (e. g. en n. 32 p. 524 debería decir 11.7.4; en línea 4 p. 221, 11.4.3 en vez de 11.3.3) o se deslice una letra (Roscher 1906).
} 